\title{
Research on the Development Path of Cultural and Creative Industries in the Digital Economy Era
}

\author{
Lijuan Mao \\ Graduate School, University of Chinese Academy of Social Sciences, Beijing, China \\ Email:maoljuan@foxmail.com
}

How to cite this paper: Mao, L. J. (2020). Research on the Development Path of Cultural and Creative Industries in the Digital Economy Era. American Journal of Industrial and Business Management, 10, 1237-1249. https://doi.org/10.4236/ajibm.2020.107082

Received: June 22, 2020

Accepted: July 20, 2020

Published: July 23, 2020

Copyright $\odot 2020$ by author(s) and Scientific Research Publishing Inc. This work is licensed under the Creative Commons Attribution International License (CC BY 4.0).

http://creativecommons.org/licenses/by/4.0/

\section{(c) (i) Open Access}

\begin{abstract}
In November 2016, the "Thirteenth Five-Year Plan for the Development of National Strategic Emerging Industries" issued by the State Council added digital creative industries. It was the first time that digital creative industries were included in the national strategic emerging industries, which means the development of digital creative industries entered a new stage. The rapid development of the digital economy has affected and impacted the cultural and creative industries. This article explains the connotation and characteristics of the cultural and creative industries in the digital economy era, and analyzes the development path of the cultural and creative industries. The cultural and creative industries in the digital economy era is based on the cultural industry, combined with digital technology, with the creative knowledge of individuals or enterprises as the core, the production creation process and results have added value of the cultural industry; the cultural and creative industries in the digital economy era is innovative, economic and networking. After a brief analysis of the current problems in the cultural and creative industries, this article proposes to strengthen the intellectual property protection of the cultural and creative industries, improve the cultural and creative industries talent training system, improve the cultural and creative industries policies and management mechanisms, gain a foot on the global cultural and creative market, and open minds to develop cultural and creative industries.
\end{abstract}

\section{Keywords}

Digital Economy, Digital Technology, Cultural Creativity, Innovation

\section{Introduction}

In the report of the $19^{\text {th }}$ National Congress of the Communist Party of my coun- 
try, Comrade Xi Jinping emphasized that socialism with Chinese characteristics has entered a new era, and the main contradiction in our society has been transformed into the contradiction between the people's increasing needs for a better life and the unbalanced and inadequate development. Especially after entering the digital economy era, the rapid development of digital technology has brought new developments and new changes to the cultural and creative industries, including new products, new industries and new models. Therefore, the contradiction between the people's growing needs for a good life and the unbalancing and insufficient developments is particularly evident in the field of cultural and creative industries. Deeply understanding and grasping the connotation of cultural and creative industries in the era of digital economy, clarifying the characteristics and development problems of cultural and creative industries in the era of digital economy, clarifying the future development path of cultural and creative industries, and promoting the development of cultural and creative industries can better meet the people's growing need for a better life.

The definition of digital economy is a series of economic activities that use digitized knowledge and information as key production factors, modern information networks as important carriers, and effective use of information and communication technologies as an important driving force for efficiency improvement and economic structure optimization. We are already in the era of the digital economy, and we treat the digital economy as the engine driving economic growth. According to a report released by the China Business Research Institute, China's total digital economy reached 31.3 trillion yuan in 2018, $34.8 \%$ of GDP, which is becoming the core and key force of China's national economic development. There are two characteristics of digital economy; one is that it applies digital technology to promote the upgrading and transformation of traditional industries by generating new economic forms; the other is that the information, knowledge, digital content, digital products, etc. contained in the digital can be used as important productive factors to accelerate the reorganization of resources, to enhance the ability of industrial innovation and creativity and to increase total factor productivity so as to promote economic growth.

China has formulated a series of policies to promote the development of the digital economy, which means the digital economy is of great significance to the national development strategy. In 2005, "Several Opinions of the State Council on Accelerating the Development of E-commerce" marked that the digital economy represented by e-commerce had become an important part of the national strategy; the "G20 Digital Economy Development and Cooperation Initiative" adopted in September 2016 proposed some consensus, principles and key areas for the digital economic development and cooperation; in November 2016, the "Thirteenth Five-Year Plan for National Strategic Emerging Industries Development" issued by the State Council newly added a digital creative industry into the national strategy, which was listed as the five new pillars with the new generation of information technology, biology, and advanced manufacturing, low-carbon in- 
dustries; the "Thirteenth Five-Year Plan for National Strategic Emerging Industries Development" also pointed out that "digital technology is deeply integrated with cultural creativity and design services; the digital creative industry has gradually become an intelligence-intensive industry that promoting high-quality products and services, and the digital economy as an effective supply of is emerging". The rapid development of the digital economy has also affected and impacted the cultural and creative industries. The rapid popularization of the network platform has extended and expanded the cultural and creative industries chain. Taking the sports industry as an example, the network platform provides a platform for live broadcasting and watching sports events. It allows users to participate in sports events anytime, anywhere. In addition, the network platform also makes it easier for users to purchase and redeem prizes through the online purchase of sports lotteries. Taking the publishing industry as an example, the digital economy era has brought digital reading methods, users can read anytime, anywhere through mobile phones, tablets, etc., and the price is even cheaper.

The rapid development of digital technology has brought new development and new changes to the cultural and creative industries, including new products, new industries and new models, which have changed the connotation and extension of the cultural and creative industries. Therefore, it is necessary to pay attention to such impacts. This article will analyze the connotation of cultural and creative industries in the era of digital economy, discuss the characteristics of cultural and creative industries in the era of digital economy, and try to build a development path for cultural and creative industries.

\section{Analysis of the Connotation of Cultural and Creative Industries in the Era of Digital Economy}

Accurate understanding of the connotation and extension of cultural and creative industries is the prerequisite of constructing the development path of cultural and creative industries. Similar to the concept of cultural and creative industries, there are cultural industries, creative industries, and creative economies. Even in the field of theoretical research, there is no unified title or definition for cultural and creative industries in the existing research literature. The definition of the cultural and creative industries originated from the "Creative Industry Path Document 1998" issued by the British government in 1998. It believes that creative industries are "those skills and talents derived from personal creativity that can be developed and used through intellectual property, which are a collection of industries that can fully exploit the potential for wealth creation and increase employment opportunities", including advertising, architecture, art and antique markets, handicrafts, design, fashion design and audiovisual, interactive leisure software, music, performing arts, publishing, software and Computer services and television broadcasting industries. The US and Canadian government's definition of cultural and creative industries puts more emphasis 
on the intellectual property rights and copyrights of cultural services and related industries; the EU emphasizes on products and services related to the results of cultural and creative activities. Although these definitions are not the same, they all emphasize creative activities in the production and dissemination of cultural products.

In the era of the digital economy, in addition to the integration of "creative knowledge" in the production and dissemination of cultural products, cultural and creative industries have begun to merge with digital technologies, which has led to changes in the industrial form. On the basis of traditional industries, the scope of industry has been expanded and new development space has been opened. Reconsolidate the cultural spirit with the help of digital means. Today, applying natural language processing technology only requires the help of an ordinary computer, which can automatically segment words in an ancient vernacular work such as A Dream of Red Mansions in a few minutes. This systematic and quantitative analysis method not only has high efficiency, but also finds omissions in previous studies, and integrates different works for cross analysis to extract a more complete cultural system. Reintegrate representative cultural elements with the help of digital technology. Using 3D scanning, image recognition, web crawler and other technologies, we can build our own cultural materials for specific years, specific regions, and specific cultures from sources such as physical objects, pictures, and texts, and then extract representative cultural element libraries to maintain cultural characteristics. At the same time, it promotes the development of cultural integration and integration, and creates more cultural products that are in line with the characteristics of the times and unique, using digital technology as a carrier to further expand the "value-added economy" of cultural products. In recent years, a series of programs reflecting Chinese culture have been highly sought after, and their influence has expanded to overseas regions. With the rise of these works, the peripheral products and activities formed with these works as the center also followed into a vigorous development period, forming a large market wave. Some Chinese original online literary works have been well received by consumer groups through adaptations of online dramas, adaptations of movies, and development of offline surroundings. The promotion of cultural products in the era of digital economy sometimes has the characteristic of marginal cost tending to zero. Re-innovate the business model of supporting the cultural industry with information technology. In the field of cultural and creative product design, some service providers have not yet reached the stage of precise identification, personalized service and differentiated supply in terms of satisfying the user's characteristic and differentiated needs. New technologies bring about potential business model changes. It is necessary to make full use of information technology to promote the formation of a platform model that matches the development trend of the digital economy, develop new economies, cultivate new kinetic energy, and cultivate high-quality cultural and creative industries in the new era. Therefore, we must fully under- 
stand the connotation of cultural and creative industries in the era of digital economy.

The cultural and creative industries in the era of digital economy are also called digital content industries and digital creative industries, which is considered from the perspective of the extension of cultural and creative industries. UNESCO's definition of a cultural and creative industries emphasizes the combination of the creative activity high technology. Zhou and Xia (2007) believes that the digital creative industry is an industrial form of the cultural creative industry, which is "based on cultural resources, using modern digital technology, network technology, modern communication technology and mass spreading technology, mainly including activities that relying on people's creativity and skills as motivation to create, disseminate and trade through digital and networked production methods, it also includes activities that use cultural creativity and new technologies to improve traditional culture industry value-added". Wang and Zhang (2018) defined the cultural and creative industries in the digital economy era as "an industry that based on creative resources, using modern digital technology, network technology, mass communication technology, and the cultural value is created and spread through digital and networked production methods by creativity-driven enterprises". Sun et al. (2019) defined it as "a newly industrial collection that is based on digital creative technology equipment and innovative design, taking cultural creativity, content creation, and copyright utilization as the core development direction, empowering peripheral industries". In summary, the cultural and creative industries in the digital economy era are based on the cultural industries and cultural resources, combined with modern digital technology, based on the core of individuals or enterprises, have added value in the process and result of creation.

This article believes that, to grasp the connotation of the cultural and creative industries in the digital economy era, we should pay attention to these aspects: First, digital. The core of the cultural and creative industries in the digital economy era is digitality. The changes brought by digital technology have changed the original industrial form of the cultural industry, restructured the productive, and disseminative processes of the cultural industry, and the creative value has been further highlighted. The creativity here is not only those related to the content of the cultural industry, but an important link in digitalized life services and manufacturing, its connotation and extension have changed accordingly. Second, cultural. Although digitality and creativity are the core of the cultural and creative industries in the era of digital economy, their essence is still culture. If there is no culture, there's no cultural and creative industries. The cultural and creative industries in the digital economy era bear cultural responsibilities and cultural missions, are an integral part of cultural construction and cultural services, and should grasp the changing trends from the height of the digital economy and promote the development of cultural and creative industries. Third, dynamic. The advent of the digital economy era means digital technology 
innovation, which is in a state of continuous development and exploration. Therefore, we should continue to explore the connotation of the cultural and creative industries with open and dynamic mind.

\section{The Main Characteristics of Cultural and Creative Industries in the Era of Digital Economy}

Caves (2002) summarized the characteristics of the cultural and creative industries into seven, including the uncertainty of demand for creative products. Jin (2006) believes that cultural and creative industries have multi-level, dynamic and personalized industrial characteristics. The cultural and creative industries in the era of digital economy has more new features: Lan and Dou (2019) believe that the digital cultural industry has the characteristics of productive digitization, disseminative network, and consumptive informationization; Zhang (2019) summarized the characteristics as the networking industrial organizations and the ecological and opening productive process. By reviewing the previous literature on the industrial characteristics of cultural and creative industries in the era of digital economy, this article summarizes the characteristics of cultural and creative industries in the era of digital economy as innovative, economical, and networked.

\section{1) Innovation}

The cultural and creative industries is based on cultural resources, forming a variety of products or services through processing personal knowledge and ideas through digital technology and ultimately. Among them, innovation is the core of the cultural and creative industries, and the value of the industry can be maximized through behaviors such as discovery, creation, and innovation. Although cultural creative products or services must rely on specific cultural resources, including cultural resources such as the historical traditions and geographical characteristics of specific regions, if there are no mental workers such as designers, planners, or artists using technologies or tools to integrate and display them in a unique form. It is impossible to form a variety of cultural and creative products or services, and it is impossible to form a cultural and creative industries. Creative workers excavate and organize historical and cultural content (folk culture, historical legends, tourism resources and other traditional cultural materials) of a specific country or region through creative mind, and use certain technical means to re-create these materials to produce cultural creative products or services which are in line with the times value. For example, the animation "Luo Xiaohei ZHANJI" combines computer design technology and ancient Chinese myths and characters to form a new cartoon that conforms to contemporary values. The novel "Pretender" is based on the multi-faced undercover Yuan Shu in the history, created a figure who spied in several parties for the ultimate victory of our party, the story was finally made into a TV series which was very popular. Guangzhou Red Brick Factory Creative Park, Shanghai M50 Creative Park, Beijing 798 Art District and other special cultural creative 
parks have all transformed historical buildings into an artistic park (see Figure 1 and Figure 2). These parks have formed artistic value and tourism value. Therefore, it can be seen that one of the core characteristics of the cultural and creative industry is its innovation.

\section{2) Economic}

Economic growth has always been an important topic in economic research. Among them, endogenous growth theory emphasizes that technological progress is endogenous, and capital accumulation and innovation are important forces that promote technological progress and economic growth. Among the endogenous growth theory, Schumpeter's growth theory "emphasizes the prominent role of innovation, $\mathrm{R} \& \mathrm{D}$ and knowledge accumulation in promoting technological progress

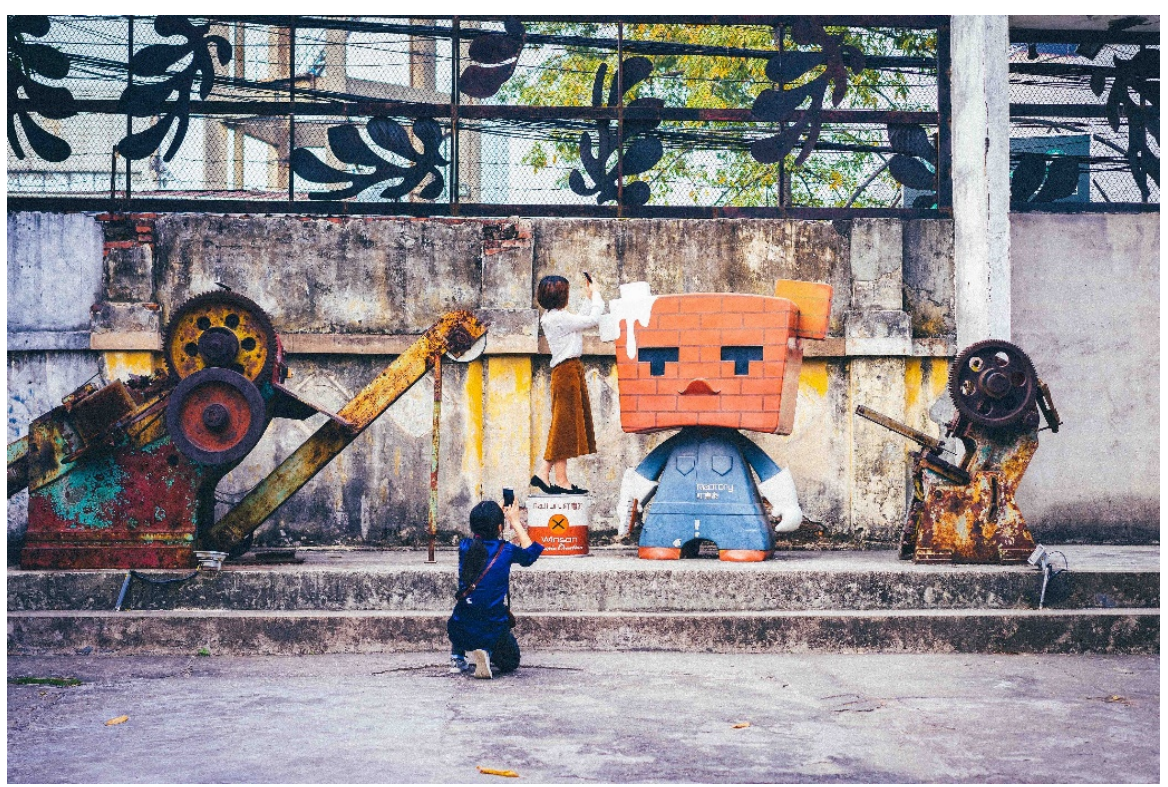

Figure 1. Guangzhou red brick factory creative park.

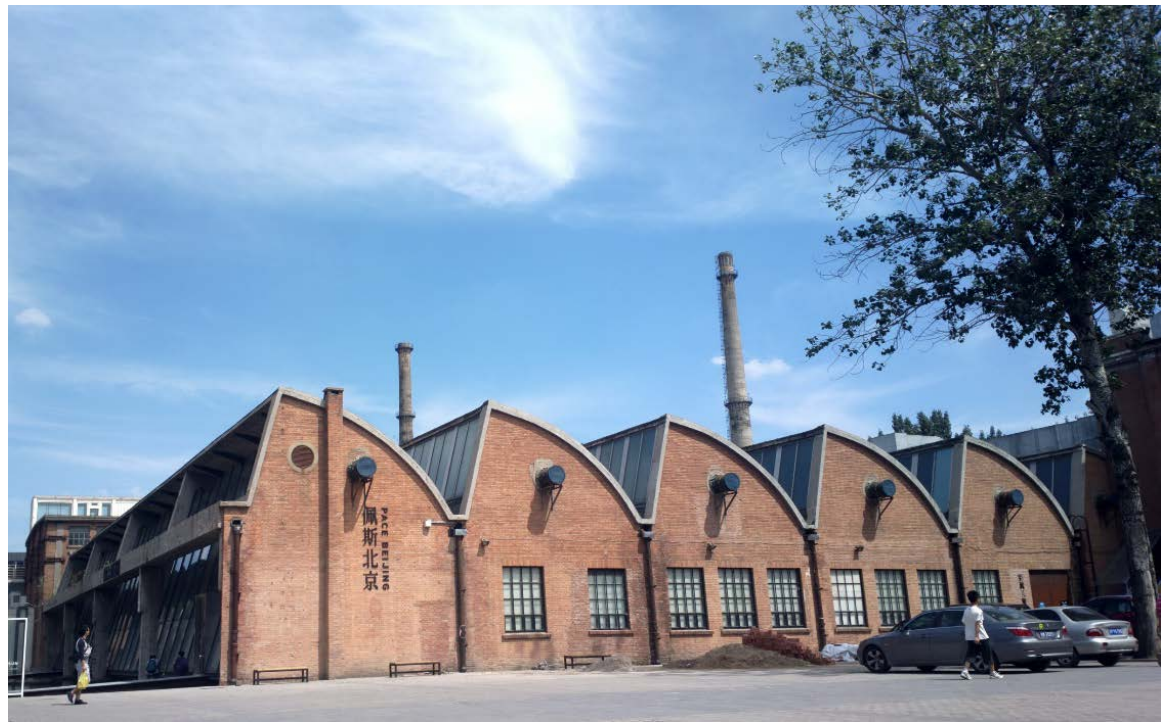

Figure 2, Beijing 798 art district. 
and economic growth, so it is also called R\&D-based growth theory and knowledge-based growth theory, innovation-based growth theory and thought-based growth theory" (Yan \& Gong, 2009). Whether cultural creativity is considered to be knowledge innovation, technological innovation themselves, or the systems and concepts contained in cultural creativity, cultural creativity can be understood as an endogenous factor of economic growth according to endogenous growth theory.

The cultural and creative industries depend on the input of cultural resources, and knowledgeable creativity. Once invested and accepted by the market, the marginal cost decreases and the marginal income increases. Therefore, the scale of the cultural and creative industries can bring higher economic benefits. Second, the core of the cultural and creative industries is creative innovation. Individuals can obtain higher economic returns through this industry, thereby attracting more people in the society to engage in knowledgeable and intellectual activities in the cultural and creative industries, promoting the accumulation of social innovation and promoting the accumulation of social human capital, in turn, bringing about the scale effect of the cultural and creative industries and generating higher returns. In addition, digital technology, as an advanced technology born through knowledge accumulation, R\&D and innovation, can also be regarded as an endogenous factor of economic growth and a new engine of economic growth. On the basis of the cultural and creative industries, using digital technology associated with other industries can produce various cultural and creative products, such as e-books, games, video, etc., which can change the original industrial form of the cultural into an industry that have better scale effects and bring higher marginal benefits to the cultural and creative industries. In summary, it can be considered that the cultural and creative industries in the digital economy era have higher economic returns and obvious economic characteristics.

\section{3) Networking}

John Earry believes that there are three types of relationship structures: chain type, central type and network type. Among them, the chain type is mainly spread out in a linear manner, the central type is spread out through one or more centres, and network type spreads information in all directions simultaneously in the network. The way of information transmission in the industrial era is usually unidirectional and centralized, so that the industrial organization relationship can only be chain type or central type, and the industrial organization form tends to be top-down; in the digital economy era, the development of digital technology, especially the development of Internet and social network media technology, has made the way of information transmission begin to be network type, which is more flexible and adaptable than the chain type and central type.

The cultural and creative industries in the era of digital economy also show the characteristics of network structure. The network structure of the cultural and creative industries is first manifested in a higher degree of industrial inte- 
gration and more blurred industrial boundaries. Recalling the connotation of the cultural and creative industries mentioned above: it is based on the cultural industry and based on the development of cultural resources, combined with modern digital technology, with the creative knowledge of individuals or enterprises as the core, and it has added value to the cultural industry in both the production creation process and results. From the connotation, we can spy on the industrial integration of the cultural and creative industries, highly integrating modern information technology, network technology and traditional cultural elements, and creative elements to produce products or services that meet people's spiritual and cultural needs. In this process, digital technology has driven the division and reorganization of many industries, forming a variety of products or services and industrial value forms. For example, information network technology has diversified movies' broadcast platforms, the platforms including movie theaters, television, film music, film peripheral products, film tourism, etc. The industry boundaries are becoming more and more blurred, but the industry's return rate increase. This penetration among industries has formed a network structure of cultural and creative industries. In addition, the network structure is also manifested in the diversifying communication paths of the cultural and creative industries. The application of digital technology to the cultural and creative industries provides a variety of communication channels for the cultural and creative industries. For example, to make film and television works by using digital technology can break through the limitations of shooting and present better pictures at a lower cost; combining digital technology with satellite technology can open up a new communication path for the media industry; through digital technical means to understand users' needs by digital technical means can provide differentiated products or services. News push software and live broadcast software are good examples.

\section{Construction of the Development Path of Cultural and Creative Industries in the Era of Digital Economy}

At present, China's cultural and creative industries has formed a certain scale and has considerable international competitiveness, but due to the fact that its understanding is not uniform, it has not been a long time since the strategy began to pay attention to this industry, so the development of this industry in China still exists problems as intellectual property protection issues, mismatched talent systems, insufficient policy support (uneven development of the industry), and insufficient openness to the outside world. Related studies such as Xiao and Xia (2018), Lan and Dou (2019) have pointed out these problems. Therefore, it is necessary to build a good development path for cultural creativity to promote the sustained and rapid development of the industry in China.

1) Strengthen the protection of intellectual property rights in cultural and creative industries

At present, there are two problems in intellectual property protection in China's 
cultural and creative industries. First, the awareness of intellectual property protection is weak. This is not only manifested in the lack of attention to intellectual property issues by cultural and creative enterprises, the lack of intellectual property self-protection strategies, but also the lack of awareness of respecting other individuals' or enterprises' intellectual property, these phenomenon in the film, television, music, publishing and other industries is common. In terms of intellectual property protection in cultural and creative industries, we should learn the intellectual property protection paths from European and American countries. For example, the United States passed the Domain Name Rights Protection Act as early as 1999 to protect enterprises' online business activities from illegal exploitation which was trying to create a fair and free environment provides guarantees. The intellectual property protection path of China's cultural and creative enterprises should combine with the actual situation so as to select the most suitable protection path. The protection path includes copyright protection mode, patent right protection mode, trademark right protection mode, trade secret and unfair competition law protection mode, contract law protection mode, etc. Although the copyright law is only for written works, it is the simplest to activate its protection mode. The patent law protects the idea of invention and the essence it implies whose protection is the strongest among all forms of legal protection, but its limitation lies in the higher protection threshold. The trademark protection can protect the ownership of trademark rights, and prevent the production of counterfeit and shoddy products, the most effective method of trademark protection is usually combined with the patent protection law to better achieve the legitimate competitive position of the creative products in the market. A large number of innovative and creative products, such as the logic and algorithms of computer software programs, can be protected using trade secrets and anti-unfair competition laws. The contract protection law is a method for protecting ideas that are still in a secret state. Cultural and creative enterprises in China need to know the path of intellectual property protection in order to make the right choice that suits themselves best.

2) Improve the talent cultivation system of cultural and creative industries

The core connotation of the cultural and creative industries is innovation, and the realization of innovation mainly depends on creative talents. It can be said that talents are the most important resource in the cultural and creative industries. Creative talents have the following characteristics: full of innovative spirit, strong desire for self-realization and desire for freedom, strong team awareness, and good cultural and artistic literacy (Xia et al., 2017). Compared with western countries, China's cultural and creative industries started late. To stand firm in the global cultural and creative market, a large number of creative talents with an international perspective and innovative capabilities are needed. First, make full use of the resources from enterprises, universities and research institutions to establish a culture and creative talent cultivation base to cultivate more com- 
pound talents for this industry. Second, give financial support to the cultivation of creative talents, and provide creative talents with entrepreneurship education, entrepreneurial investment and financing services in creative industry so as to attract more creative talents. Third, establish an talent management mechanism to mobilize the enthusiasm of creative talents. In addition, it is necessary to create a comfortable working and living environment for creative talents so as to attract creative talents and retain creative talents, only in this way, the cultural and creative industries can be fully developed.

3) Improve cultural and creative industries policies and management mechanisms

Since entering the digital age, the cultural and creative industries has developed rapidly, but the cultural and creative industries' sustainable development needs the support of industrial policies and management mechanisms. Industrial policy is an important role for the government to guide industrial development, enhance industrial competitiveness, and achieve economic growth. On the basis of investigating the development status of the cultural and creative industries, the Chinese government needs to analyze the development mode and regional layout of its cultural and creative industries from the macro perspective, so as to formulate and improve national or regional policies to encourage the development of the cultural and creative industries. Second, appropriately plan the industrial development space, guide the construction of cultural and creative industrial parks, and guide specific projects to the corresponding industrial parks. Third, build a public service platform to form a bridge between the government and enterprises. Enterprises can use this platform to understand relevant government policies and supporting measures so as to reduce enterprise costs and improve the overall competitiveness of regional enterprises. Fourth, it is necessary to establish an institution which is responsible for the promotion of the entire industry, to ensure cross-departmental cooperation, and to jointly promote the development of the cultural and creative industries with universities, research institutions, and enterprises. Fifth, establish and improve the investment and financing system for the cultural and creative industries, set up a special fund for the cultural and creative industries, and strengthen industrialization guidance and cultivation in accordance with national and regional industrial development strategies. At the same time, the investment environment of the national and regional cultural and creative industries should be improved, and more venture capital should be introduced to develop the industry.

4) Based on the global cultural and creative market, develop cultural and creative industries with an open mind

China's current opening up in the cultural and creative industries has achieved primary results, it is still necessary to continue to increase the opening up of the cultural and creative industries on the premise of ensuring the safety of China's industrial development. Specifically, it is necessary to pay attention to the cultivation of multinational enterprises in the field of cultural creativity, in 
order to cultivate China's international cultural creative brand, enhance the international reputation and competitiveness of the industry in China; improve the international cooperation and exchange mechanism in this field, and build a cultural creativity display and exchange platform to help Chinese cultural and creative enterprises expand overseas markets more conveniently. In addition, before "going out", we must pay attention to the common characteristics and differences between countries or regions, formulate trade strategies and market positioning according to local markets; pay attention to the development of local cultural resources, and develop cultural and creative products or services according to local conditions; at the same time. It is necessary to actively use digital technology to promote the opening up of the cultural and creative industries into a newer height and depth.

\section{Conclusion}

The rapid development of the digital economy has affected and impacted the cultural and creative industries. This article explains the connotation and characteristics of the cultural and creative industries in the digital economy era, and analyzes the development path of the cultural and creative industries. The cultural and creative industries in the digital economy era is based on the cultural industry, combined with digital technology, with the creative knowledge of individuals or enterprises as the core, the production creation process and results have added value of the cultural industry; the cultural and creative industries in the digital economy era is innovative, economic and networking. After a brief analysis of the current problems in the cultural and creative industries, this article proposes to strengthen the intellectual property protection of the cultural and creative industries, improve the cultural and creative industries talent training system, improve the cultural and creative industries policies and management mechanisms, gain a foot on the global cultural and creative market, and open minds to develop cultural and creative industries. The development path of cultural creativity in the era of digital economy needs more empirical methods to verify its feasibility.

\section{Conflicts of Interest}

The author declares no conflicts of interest regarding the publication of this paper.

\section{References}

Caves, R. (2002). Creative Industries: Contracts between Art and Commerce. Cambridge, MA: Harvard University Press.

Jin, Y. P. (2006). Concept and Features of the Contemporary World Creative Industry. Film Art, No. 3, 5-10.

Lan, Q. X., \& Dou, K. (2019). Research on the Influencing Factors of International Competitiveness of China's Digital Culture Industry. Guangdong Social Sciences, No. 4, $12-22+254$. 
Sun, S. Q., Min, X., \& Tang, Y. C. (2019). Current Situation and Prospects of the Development of Digital Creative Industries. Packaging Engineering, No. 12, 65-74.

Wang, B., \& Zhang, G. (2018). Research on the Development of China's Digital Creative Industry-Based on the Perspective of the Industrial Chain. China Price, No. 3, 25-27.

Xia, J. C., Liu, W. G., \& Liu, X. D. (2017). Creative Economy-New Momentum for Shanghai's Economic Growth. Beijing: Social Sciences Literature Press.

Xiao, Y., \& Xia, J. C. (2018). My Country’s Digital Culture Industry Development Status, Problems and International Comparative Study. Globalization, No. 8, 70-86+134.

Yan, C. L., \& Gong, L. T. (2009). Schumpeter's Growth Theory: A Literature Review. Economics (Quarterly), No. 3, 1163-1196.

Zhang, X. W. (2019). Research on the Evolution of Innovation Models under the Condition of Digital Economy. The Economist, No. 7, 32-39.

Zhou, Z. Q., \& Xia, G. F. (2007). On Digital Creative Industries. Journalists (Theoretical Edition), No. 12, 14-15. 